Cipango
Cipango

17 | 2010

La péninsule retrouvée

\title{
La réorganisation des sanctuaires au Japon de l'époque Meiji à l'époque Taishō - Ōsugi jinja : dernier sanctuaire de l'ancien village de Takahashi
}

\section{Aurélien Allard}

\author{
(2) OpenEdition \\ Journals \\ Édition électronique \\ URL : https://journals.openedition.org/cipango/1150 \\ DOI : 10.4000/cipango. 1150 \\ ISSN : 2260-7706 \\ Éditeur \\ INALCO \\ Édition imprimée \\ Date de publication : 30 juin 2010 \\ Pagination : 298-300 \\ ISBN : 978-2-85837-195-8 \\ ISSN : $1164-5857$
}

Référence électronique

Aurélien Allard, «La réorganisation des sanctuaires au Japon de l'époque Meiji à l'époque Taishō Ōsugi jinja : dernier sanctuaire de l'ancien village de Takahashi », Cipango [En ligne], 17 | 2010, mis en ligne le 20 novembre 2012, consulté le 30 juin 2021. URL : http://journals.openedition.org/cipango/ 1150 ; DOI : https://doi.org/10.4000/cipango.1150

Ce document a été généré automatiquement le 30 juin 2021.

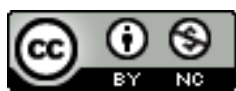

Cipango est mis à disposition selon les termes de la Licence Creative Commons Attribution - Pas d'Utilisation Commerciale 4.0 International. 


\title{
La réorganisation des sanctuaires au Japon de l'époque Meiji à l'époque Taishō - Ōsugi jinja : dernier sanctuaire de l'ancien village de Takahashi
}

\author{
Aurélien Allard
}

\section{RÉFÉRENCE}

La réorganisation des sanctuaires au Japon de l'époque Meiji à l'époque Taishō - Ōsugi jinja : dernier sanctuaire de l'ancien village de Takahashi, Mémoire de Master 2 soutenu par Aurélien Allard, sous la direction de François Macé, INALCO, 2009.

$1 \quad$ En ce début de $\mathrm{xx}^{\mathrm{e}}$ siècle, plusieurs dizaines de milliers de sanctuaires shintō ont été supprimés. Cet événement est ordinairement désigné sous le nom de «fusion des sanctuaires " (jinja gappei) de Meiji. Or cette fusion semble n'avoir été que le moyen et la conséquence d'une longue politique de réorganisation des sanctuaires sur l'ensemble de l'archipel. Ce mémoire invite à l'étude de la réorganisation des sanctuaires (jinja seiri) du début des années Meiji aux années Taishō (1868-1925).

Il s'appuie essentiellement sur trois auteurs de référence (Sakurai Haruo, Moriyoka Kiyomi et Wilbur M. Fridell) et sur certains documents de première main (témoignages, texte de lois, lettres, enquêtes, etc.) parus dans deux publications d'époque («le Bulletin d'information national des desservants shintô » et « la Revue de l'Association des sanctuaires $»)$.

3 En 1872, quatre ans près avoir expurgé le shintō du bouddhisme et avoir tenté de le promouvoir en religion d'État, le jeune gouvernement de Meiji bouleverse l'organisation des sanctuaires. Ceux-ci sont dorénavant divisés en « sanctuaires d'État » 
(kansha), où sont déposées des offrandes impériales, et en "sanctuaires du peuple " (minsha). Ces derniers sont classés selon leur importance en "sanctuaires de département ", "de district ", "de village " et en "sanctuaires sans rang». Leurs desservants deviennent des fonctionnaires et perdent leur charge héréditaire ainsi que leurs avantages fonciers. Il s'agit désormais pour eux de se dévouer au culte de la nation (kokka no sōshi) incarnée par l'empereur. Quand, en octobre 1897, les desservants des sanctuaires d'État voient à leur tour leurs prérogatives menacées, ils créent "l'Association nationale des desservants shintō» (Zenkoku shinkoku kai) qui milite pour le rétablissement du ministère des Dieux et le financement public des sanctuaires. Cette association obtient rapidement un premier succès avec la création d'un Bureau des sanctuaires (Jinja kyoku), distinct du Bureau des religions (Shūkyō kyoku). Elle échoue de peu en 1901 à faire voter une loi de financement public des offrandes.

Toutefois dans plusieurs départements, à commencer par celui de Mie (terre du grand sanctuaire d'Ise, centre du culte impérial), des ébauches de fusions et de dons d'offrandes officielles apparaissent et préparent les esprits. En 1906, l'édit impérial $n^{\circ} 96$ sur le financement public des offrandes est promulgué. Alors s'enchainent les lois et les directives ministérielles. De stricts critères de sélection des sanctuaires destinés à devenir les centres des fusions qui recevront les offrandes sont fixés (nombre et superficie des bâtiments, équipement de l'enceinte, budget annuel, nombre de paroissiens, etc.). Ceux-ci diffèrent toutefois selon les départements. Le délai imposé aux communautés et l'échelle des fusions (un sanctuaire par village ou un sanctuaire par hameau) donnent d'ailleurs des résultats très différents d'un département à l'autre. Si certains, comme ceux de Nagasaki, Kyōto ou Nara, ont connu une baisse de moins de $20 \%$ de leurs sanctuaires sans rang (les plus nombreux), d'autres, Ehime, Gunma ou Akita, ont connu une réduction supérieure à $80 \%$. Seuls les départements de Mie, Wakayama et Ōsaka sont marqués par une très forte diminution à la fois de leurs sanctuaires de village et de leurs sanctuaires sans rang.

5 La fusion d'un grand nombre de sanctuaires a certes été motivée par le gain financier rendu possible par l'appropriation des enceintes sacrées et de leurs forêts. On peut penser pourtant qu'il s'agissait en premier lieu d'une mesure participant à la politique de suppression des hameaux qui auraient dû disparaitre lors de la création des nouvelles délimitations des bourgs et villages, alors que les sanctuaires étaient définis comme de nouveaux centres administratifs, sociaux et éducatifs.

6 Cette politique s'est heurtée à l'opposition active ou passive de la population. Minakata Kumagusu a imposé le débat dans les travées de l'assemblée et a trouvé un écho favorable auprès du nouveau ministre de l'Intérieur, Hirata Tōsuke. D'autre part, l'étude de certains hameaux du département de Mie témoigne de vives réactions: revendications d'indépendance, adoptions de nouvelles divinités, cultes en dehors des sanctuaires ou encore refus de se présenter aux célébrations officielles. À partir de 1912, certaines communautés auront même recours à la «reconstruction de leur sanctuaire tutélaire » (jinja fukushi), parfois officiellement reconnue.

7 La seconde partie de ce mémoire est le résultat de nombreuses enquêtes de terrain menées entre 2006 et 2009 dans la municipalité d'Imabari du département d'Ehime et porte sur le cas de l'ancien village de Takahashi. Celui-ci était divisé en cinq grands hameaux, auxquels ne répondaient étonnamment pas autant de sanctuaires tutélaires. Sa partition était à la fois historique et géographique : au nord, vers la montagne, se situaient Hongō et le sanctuaire tutélaire de Kobayashi Hachiman; au sud, vers les 
rizières, Shinden et le sanctuaire tutélaire d'Ōsugi. L'ensemble du village se réunissait au sommet du mont d'Iyo Kumano lors des célébrations du sanctuaire éponyme aux origines shintô-bouddhiques. Au cours de la réorganisation, les trois sanctuaires ont fusionné avec celui d'ōsugi et ont migré sur le mont d'Iyo Kumano. Une vingtaine de sanctuaires subsidiaires et sans rang ont été déplacés ou ont fusionné donnant naissance à de petites chapelles (hokora) réunies à l'intérieur d'un bâtiment en bois (La porte aux deux rois). Avec l'aide du desservant Takada Hideshi et de M. Ochi Tadayuki, notre découverte d'un relevé des anciens sanctuaires et d'une carte de leurs emplacements a permis d'identifier et de localiser 22 sanctuaires dont les traces s'étaient estompées. Seul le sanctuaire subsidiaire d'Inari a demeuré sur les terres de l'actuel sanctuaire d'ōsugi, en raison de son importance historique pour les anciens seigneurs du fief d'Imabari.

8 La communauté de Takahashi, déjà habituée à célébrer ses divinités sur le sommet du mont Iyo Kumano, ne semble pas avoir montré une forte opposition à la suppression de ses nombreux sanctuaires. Cependant, elle perpétue encore leur culte et leur mémoire. Les trois emblèmes des sanctuaires parsèment les bâtiments et les murs de l'enceinte actuelle. La cérémonie d'Inari du sanctuaire éponyme fait écho à celle d'Iyo Kamano et partage la même appellation populaire (fête de l'avatar). De petits sanctuaires portatifs (mikoshi) aux couleurs de Hongō et de Shinden sont portés par les écoliers lors des cérémonies d'automne et de printemps. Un groupe de maisons conserve à tour de rôle une petite chapelle du sanctuaire de Kobayashi Hachiman et de trois de ses sanctuaires subsidiaires et les célèbre au cours d'un banquet annuel (otosan).

9 Si au fil de l'histoire, les divinités ont pu être amenées à changer de nom et de forme, la suppression de leurs sanctuaires ou autres lieux n'en a que peu altéré leur culte. De nos jours, nombreuses sont les recherches qui portent sur l'État et la société japonaise à l'époque moderne. L'étude de la réorganisation des sanctuaires, et au-delà, celle du culte des divinités dans un Japon moderne et contemporain leur apporterait sans doute un nouvel éclairage. 